\title{
Adequate versus inadequate weight gain and socioeconomic factors of pregnant women followed up in primary care
}

Luciane Oliveira da Silva 1

https://orcid.org/0000-0003-0095-0711

Mayara Ribeiro Alexandre 2

https://orcid.org/0000-0003-0454-2010

Ana Carolina Montenegro Cavalcante 3

https://orcid.org/0000-0002-1086-0587

Soraia Pinheiro Machado Arruda 4

https://orcid.org/0000-0002-3918-4738

Rafaella Maria Monteiro Sampaio 5

https://orcid.org/0000-0001-9994-1916

1,2 Centro Universitário Estácio do Ceará. Fortaleza, CE, Brasil.

3,5 Universidade de Fortaleza. Av. Washington Soares, 1321, Edson Queiroz. Fortaleza, CE, Brasil. CEP 60.811-905. E-mail: rafaellasampaio@yahoo.com.br 4 Universidade Estadual do Ceará. Fortaleza, CE, Brasil.

\begin{abstract}
Objectives: to identify the socioeconomic factors associated with inadequate (excessive and insufficient) weight gain in women followed during prenatal care in Basic Health Units in a Municipality of the Countryside of Ceará.

Methods: a study was carried out with 189 pregnant women. Data were tabulated in the Excel Program and data analysis was performed in the Stata Program. In the bivariate analysis, the chi-square or Fisher's exact test was used, and the Poisson multivariate regression was used for the association between variables and the excessive or insufficient weight gain.

Results: insufficient weight gain was associated with the absence of the partner ( $R R=1.15$ $C I 95 \%=1.02-1.30)$ and excessive weight gain was associated with non-working women $(R R=0.90 C 195 \%=0.84-0.96)$.

Conclusions: absence of partner and lack of work were associated with inadequate weight gain during pregnancy.
\end{abstract}

Key words Pregnant women, Prenatal care, Overweight

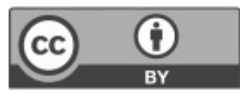




\section{Introduction}

Inadequacies in weight gain during pregnancy are important predictors of complications for mother and child. The weight gain is one of the main changes that occur during pregnancy. It is distributed from the conception until birth in several components, such as fetus, placenta, amniotic fluid, blood volume of the mother, besides uterine and mammary gland enlargement, each one of them being gradually modified during gestation. ${ }^{1-3}$

The high variation in weight gain of healthy pregnant women seems to be determined by different maternal characteristics. Among these, adverse socioeconomic conditions are relevant factors that generate gestational risks. In general, these situations are associated with stress and inadequate nutritional conditions. 4,5

Teen pregnancy, pre-gestational low weight, low income, low education level, smoke habit, alcohol and drug consumption during pregnancy contribute to insufficient gestational weight gain. ${ }^{3}$ However, excessive weight gain during gestation is associated to a minimum age of 35 years, pre-gestational overweight and obesity, presence of companion, alcohol consumption during pregnancy and working outside the home.6,7

An early identification of possible risk factors associated with inadequate weight gain during pregnancy is indispensable to allow effective and opportune interventions 8 that may reverse or ease unfavorable gestation outcomes. Hence, this study aimed to identify socioeconomic factors associated with inadequate weight gain (excessive and insufficient) in women during pre-birth follow ups in basic health units in a city of Ceará State.

\section{Methods}

A transversal study was performed with 189 pregnant women distributed among 17 (85\%) basic health units in Horizonte city, Ceará State, between August and September 2015. The remaining 15\% of the City units were not included due to difficulties the researchers had to access them. Sampling was performed with a questionnaire to acquire data concerning age, marital status, pregnancy planning, occupation, education level, income and habitation.

All individuals in waiting rooms for medical consultation of pre-natal exams were invited to participate in the research. Age limits or pregnancy stage were not used as inclusion criteria. After reading and explaining the consent term, pregnant women that agreed to participate were interviewed by the authors of this study. Initially, sampling included 210 individuals, which represented $37.2 \%$ of the population of pregnant women in the city at the period, which was of 564 women according to data from the City Health Secretary. For the analysis in this study, 189 pregnant women were selected due to the absence of information concerning pre-gestational weight in 21 record books of the individuals.

During the first interview, pregnant women were instructed to remove their shoes for current weight evaluation, which was assessed in digital scale (FILIZOLA ${ }^{\circledR}$ ) that had a capacity of $180 \mathrm{~kg}$ and $100 \mathrm{~g}$ graduation. Height was measured with a SANNY portable stadiometer with a $0.1 \mathrm{~cm}$ precision. Individuals were asked to remain erect with extended arms lateral to the body. Anthropometric data referring to pre-gestational period were obtained from the record books.

Weight gain adequacy was evaluated according to the estimated weight gain recommended by the Ministry of Health. 9 Through the pre-gestational nutritional state, the ideal recommendation until this period was compared to the calculation described in Table 1 and attributed to insufficient, adequate or excessive weight gain categories. A $1 \mathrm{~kg}$ variation for more or less of the calculated estimate was considered as an adequate weight gain. Superior or inferior variations were considered as excessive or insufficient weight gain, respectively. In the first trimester, independently of previous anthropometric state, pregnant women that lost up until $3 \mathrm{~kg}$ of weight were classified in the adequate weight gain category.

For best comprehension, an example is described. A pregnant woman considered eutrophic according to pre-gestational Body Mass Index (BMI) with weight gain of $15 \mathrm{~kg}$ in the $30^{\text {th }}$ week of pregnancy (weight gain: actual weight in the $30^{\text {th }}$ week minus pre-gestational weight verified in the record book). According to the literature (Table 1), the ideal weight gain would be $[1.6 \mathrm{~kg}$ ( 1 st trimester $)+6.8 \mathrm{~kg}$ $(17$ weeks $\times 0.4 \mathrm{~kg})]$, which would render a total of $8.4 \mathrm{~kg}$ at the $30^{\text {th }}$ pregnancy week. Hence, this individual was classified in the excessive weight gain category, considering that she had gained $15 \mathrm{~kg}$.

For statistical analyses, data were collected and organized in the EXCEL software. Then, data were processed and analyzed with STATA v.10.0 software, in which the categorical variables were tabulated in simple and percentage frequencies. Numeric variables, such as age and income, were dichotomized to reduce categories. For the bivariate analysis, chisquare test or Fisher's exact test was used considering a significance level of $p<0.05$. 
Recommendation of weight gain for pregnant women.

\begin{tabular}{lccccc}
\hline $\begin{array}{l}\text { Classification of pre } \\
\text { gestational nutritional status }\end{array}$ & \multicolumn{5}{c}{$\begin{array}{c}\text { Recommendation of ideal weight gain by } \\
\text { quarter and based on previous nutritional status }\end{array}$} \\
\hline & & Up to $13 \mathrm{GW}$ & 14 to 27 & 27 to 36 & From 37 \\
\cline { 2 - 6 } & 2.3 & $2.3+0.5 /$ week & $8.8+0.5 /$ week & 12.5 a $18.0 \mathrm{Kg}$ \\
Low weight & 1.6 & $1.6+0.4 /$ week & $6.8+0.4 /$ week & 11.5 a $16.0 \mathrm{Kg}$ \\
Eutrophic & 0.9 & $0.9+0.3 /$ week & $4.8+0.3 /$ week & 7.0 a $11.5 \mathrm{Kg}$ \\
Overweight & 0.0 & $0.0+0.2 /$ week & $2.6+0.2 /$ week & 5.0 a $9.0 \mathrm{Kg}$ \\
Obesity & & & & &
\end{tabular}

Source: Brazil, Ministry of Health.8; GW= gestational week.

The association between evaluated variables and excessive or insufficient weight gain was verified using a Poisson regression model with robust variance. Initially, a bivariate analysis was performed to evaluate possible associations between the socioeconomic variables (independent variables) and gestational weight gain (dependent variable). In this procedure, probability inferior to $5 \%$ was considered as a statistic significant level for the selection in the multiple Poisson regression model. Variables that presented statistically significant association with $p<0.20$ were included in the multiple regression analysis.

This study was performed in accordance with regulation (document 466/12) and approved by the Ethics Committee for Research in the University Center Estácio do Ceará with protocol number 53026015.4.0000.5038. All pregnant women signed the consent form.

\section{Results}

From the total of 189 analyzed pregnant women, 97 $(51.3 \%)$ had excessive weight gain, $30(15.9 \%)$ presented insufficient weight gain and $62(32.8 \%)$ had adequate weight gain in the moment of data collection. Data were analyzed in two ways; by comparing the ones classified as having adequate weight gain with the ones with excessive weight gain (Table 2) and adequate with insufficient weight gain (Table 3).

Table 2 presents the comparison between pregnant women that had adequate weight gain with those that had excessive rates and independent variables. In this first analysis, individuals with insufficient weight gain were excluded. Results demonstrated that $39 \%$ of pregnant women had adequate weight gain and $61 \%$ presented excessive weight gain. The excessive weight gain was predominant in adults $(62.8 \%)$, in women with companions $(62 \%)$ and in those that worked (71.6\%) in comparison to teens, respectively.

Concerning the planning of pregnancy, education level, location of the house and income, percentage values presented for each dichotomized variable were similar between women with adequate and excessive weight gain (Table 2). Therefore, there was no statistical significance.

In the multivariate Poisson analysis, results demonstrated that women that did not work presented less chance for an excessive weight gain $[\mathrm{RR}=0.90(\mathrm{CI} 95 \%=0.84-0.96)]$.

Table 3 demonstrates the association between pregnant women with adequate weight gain versus those with insufficient weight gain and remaining variables. For this analysis, those with excessive weight gain were excluded. Hence, $68 \%$ presented adequate weight gain and $32 \%$ were insufficient. Insufficient gestational weight gain was more frequent in adults (33.3\%); with no companion (50\%); unplanned pregnancy $(37.2 \%)$; employed (34.4\%); unfinished high school (35.5\%); rural area residents and those with income lower than 1.5 minimum salaries (35.1\%).

Multivariate Poisson analysis confirmed that women with no companion presented higher chance of having insufficient weight gain $[R R=1.15$ $(\mathrm{CI} 95 \%=1.02-1.3)]$. In addition, women in rural areas also presented a tendency for insufficient weight gain $[R R=1.09(\mathrm{CI} 95 \%=0.99-1.20)]$.

\section{Discussion}

In this study, results demonstrated frequent occurrence of inadequate gestational weight gain, in which excessive $(51.3 \%)$ and insufficient $(15.9 \%)$ cases occurred. Hence, only $32.8 \%$ of pregnant women had adequate levels of weight gain. The increase of excessive weight gain during gestation is frequently associated with obesity among women. 
Table 2

Multivariate analysis between the variables under study and weight gain (adequate versus excessive). Horizonte (CE), 2015.

\begin{tabular}{|c|c|c|c|c|c|c|c|c|c|c|}
\hline \multirow[t]{2}{*}{ Variables } & & \multicolumn{2}{|c|}{ Total } & \multicolumn{2}{|c|}{ Adequate } & \multicolumn{2}{|c|}{ Excessive } & \multirow[t]{2}{*}{$\mathbf{R R}$} & \multirow[t]{2}{*}{$\mathrm{Cl} 95 \%$} & \multirow[t]{2}{*}{$p$} \\
\hline & & $\mathrm{n}$ & $\%$ & $\mathrm{n}$ & $\%$ & $\mathrm{n}$ & $\%$ & & & \\
\hline \multicolumn{11}{|l|}{ Age (years) } \\
\hline$<20$ & & 30 & 100.0 & 14 & 46.7 & 16 & 53.3 & 1.02 & $0.93-1.11$ & 0.658 \\
\hline$\geq 20$ & & 129 & 100.0 & 48 & 37.2 & 81 & 62.8 & & & \\
\hline \multicolumn{11}{|l|}{ Marital status } \\
\hline With partner & & 145 & 100.0 & 55 & 38.0 & 90 & 62.0 & 0.99 & $0.86-1.13$ & 0.912 \\
\hline Without partner & & 14 & 100.0 & 07 & 50.0 & 07 & 50.0 & & & \\
\hline \multicolumn{11}{|l|}{ Planned pregnancy } \\
\hline Yes & & 90 & 100.0 & 35 & 38.9 & 55 & 61.1 & 0.98 & $0.92-1.04$ & 0.664 \\
\hline No & & 69 & 100.0 & 27 & 39.1 & 42 & 60.9 & & & \\
\hline \multicolumn{11}{|l|}{ Insertion at work } \\
\hline Yes & & 74 & 100.0 & 21 & 28.4 & 53 & 71.6 & 0.90 & $0.84-0.96$ & $0.002 *$ \\
\hline No & & 85 & 100.0 & 41 & 48.2 & 44 & 51.8 & & & \\
\hline \multicolumn{11}{|l|}{ Schooling } \\
\hline$<$ Middle School & & 76 & 100.0 & 29 & 38.2 & 47 & 61.8 & 0.97 & $0.91-1.04$ & 0.664 \\
\hline$\geq$ High School & & 83 & 100.0 & 33 & 39.8 & 50 & 60.2 & & & \\
\hline \multicolumn{11}{|l|}{ Zone } \\
\hline Urban & & 126 & 100.0 & 48 & 38.1 & 78 & 61.9 & 0.99 & $0.92-1.07$ & 0.992 \\
\hline Rural & & 33 & 100.0 & 14 & 42.4 & 19 & 57.6 & & & \\
\hline & Total & 159 & 100.0 & 62 & 39.0 & 97 & 61.0 & & & \\
\hline \multicolumn{11}{|l|}{ Income (wages) } \\
\hline$\leq 1,5$ & & 66 & 100.0 & 24 & 36.4 & 42 & 63.6 & 0.95 & $0.88-1.01$ & 0.150 \\
\hline$>1,5$ & & 86 & 100.0 & 34 & 39.5 & 52 & 60.5 & & & \\
\hline & Total * & 152 & 100.0 & 58 & 38.2 & 94 & 61.8 & & & \\
\hline
\end{tabular}

*Four pregnant women with adequate weight gain and three pregnant women with a gain above did not respond to income. 
Table 3

Multivariate analysis between the variables under study and weight gain (adequate versus insufficient). Horizonte (CE), 2015.

\begin{tabular}{|c|c|c|c|c|c|c|c|c|c|c|}
\hline \multirow[t]{2}{*}{ Variables } & & \multicolumn{2}{|c|}{ Total } & \multicolumn{2}{|c|}{ Adequate } & \multicolumn{2}{|c|}{ Insufficient } & \multirow[t]{2}{*}{ RR } & \multirow[t]{2}{*}{$\mathrm{Cl} 95 \%$} & \multirow[t]{2}{*}{$p$} \\
\hline & & $\mathrm{n}$ & $\%$ & $\mathrm{n}$ & $\%$ & $\mathrm{n}$ & $\%$ & & & \\
\hline \multicolumn{11}{|l|}{ Age (years) } \\
\hline$<20$ & & 20 & 100.0 & 14 & 70.0 & 06 & 30.0 & 1.05 & $0.94-1.17$ & 0.346 \\
\hline$\geq 20$ & & 72 & 100.0 & 48 & 66.7 & 24 & 33.3 & & & \\
\hline \multicolumn{11}{|l|}{ Marital status } \\
\hline With partner & & 78 & 100.0 & 55 & 70.5 & 23 & 29.5 & 1.15 & $1.02-1.30$ & 0.021 * \\
\hline Without partner & & 14 & 100.0 & 07 & 50.0 & 07 & 50.0 & & & \\
\hline \multicolumn{11}{|l|}{ Planned pregnancy } \\
\hline Yes & & 49 & 100.0 & 35 & 71.4 & 14 & 28.6 & 1.02 & $0.93-1.11$ & 0.586 \\
\hline No & & 43 & 100.0 & 27 & 62.8 & 16 & 37.2 & & & \\
\hline \multicolumn{11}{|l|}{ Insertion at work } \\
\hline Yes & & 32 & 100.0 & 21 & 65.6 & 11 & 34.4 & 0.97 & $0.89-1.07$ & 0.674 \\
\hline No & & 60 & 100.0 & 41 & 68.3 & 19 & 31.7 & & & \\
\hline \multicolumn{11}{|l|}{ Schooling } \\
\hline < Middle School & & 45 & 100.0 & 29 & 64.4 & 16 & 35.5 & 0.98 & $0.89-1.09$ & 0.833 \\
\hline$\geq$ High School & & 47 & 100.0 & 33 & 70.2 & 14 & 29.8 & & & \\
\hline \multicolumn{11}{|l|}{ Zone } \\
\hline Urban & & 67 & 100.0 & 48 & 71.6 & 19 & 28.4 & 1.09 & $0.99-1.20$ & $0.050 *$ \\
\hline Rural & & 25 & 100.0 & 14 & 56.0 & 11 & 44.0 & & & \\
\hline & Total & 92 & 100.0 & 62 & 68.0 & 30 & 32.0 & & & \\
\hline \multicolumn{11}{|l|}{ Income (wages) } \\
\hline$\leq 1,5$ & & 37 & 100.0 & 24 & 64.9 & 13 & 35.1 & 1.02 & $0.91-1.14$ & 0.664 \\
\hline$>1,5$ & & 49 & 100.0 & 34 & 69.4 & 15 & 30.6 & & & \\
\hline & Total * & 86 & 100.0 & 58 & 67.4 & 28 & 32.6 & & & \\
\hline
\end{tabular}

*Four pregnant women with adequate weight gain and two pregnant women below the recommended did not respond to income. 
Studies demonstrate that the extra weight acquired during pregnancy is usually maintained after birth, leading to obstetric and perinatal negative consequences. ${ }^{10,11}$ Therefore, an early intervention in pregnant women with excessive weight gain is important, considering that it may have a positive impact and diminish frequency of obesity among women in the future. 10 In addition, it is important to note that the investigation of inadequate weight gain in this study was performed during gestation and, therefore, the individuals were performing pre-natal exams.

A prospective transversal study performed in Aracaju City, Sergipe State, with 214 pregnant women in a public maternity hospital revealed that excessive weight gain was identified in $57.6 \%$ of the individuals and only $25.2 \%$ had adequate values. 12 Those results are similar to the values presented here, in which excessive weight gain was identified in $61 \%$ of the investigated women. Another transversal study performed in 21 health units of Vitória da Conquista, Bahia State, with 328 pregnant women revealed that $51.9 \%$ of them presented excessive weight gain. 13 These data were also similar to the results identified here, in which more than half of the investigated pregnant women presented excessive gestational weight gain (51.3\%).

This condition suggests that such women did not receive adequate nutritional care or did not follow up the recommendations. It has been demonstrated that excessive weight gain presents a negative impact on growth and development of the infant and may generate complications in pregnancy and consequences for the mother after birth. 14,15 The monitoring of weight gain may be jeopardized in the absence of a nutritionist professional in many Brazilian cities, which may affect prenatal followups.

The prenatal technical manual 16 of the Ministry of Health describes the importance of care for pregnant women aiming to reduce morbidity and mortality rates in mothers and children by means of improvement of access, cover and quality of medical care. In addition, this document emphasizes the roles of the physician, nurse, health agent and nurse assistant in Family Health Strategy teams in the care of pregnant women. According to the description, the nutritional assistance must be attributed to the physician and/or nurse, which in many cases may not be prepared for a specific nutritional conduct.

It is important that individualized nutritional care to pregnant women is performed by professional nutritionists from the improved Health Family Support Nucleus or through the elaboration of proto- cols for consultation and referral. Furthermore, these professionals may aid in the formation and continued education of the professionals from Family Health Strategy teams. ${ }^{17,18}$

Concerning the companion issue, the absence of family stability throughout pregnancy may affect negatively the psychological and financial state of the mother. ${ }^{11,13}$ In this study, the risk for excessive weight gain in women with companions and the risk for insufficient weight gain for women without companions were assessed and confirmed by Poisson regression $[\mathrm{RR}=1.15(\mathrm{CI} 95 \%=1.02-$ 1.30)]. This may be explained by the fact that the marital status is an important aspect to be considerate and the absence of a father figure may bring less financial stability, which may constitute as a risk factor for the mother's nutritional status, causing a decrease in the birth weight of newborns. 19

As for pregnancy planning, there was no significant difference between groups. The incidence of adequate weight gain versus excessive and insufficient was very similar. Analyzing the employment status revealed that $71.6 \%$ presented a higher risk of excessive weight gain, compared to $51.8 \%[\mathrm{RR}=0.90$ $(\mathrm{CI} 95 \%=0.84-0.96)]$ of individuals that were unemployed. This finding was superior to a transversal study with 212 pregnant women in Botucatu City, São Paulo, in which $54.3 \%$ of women that were employed had excessive weight gain. In addition, $30.5 \%$ of individuals that had adequate weight gain were unemployed. 14 This may be associated with the fact that unemployed women have more time for pursuing a healthy diet, better prenatal follow-ups and physical activities. In addition, working may generate stress, which can lead to inadequate consumption of food. Employment was not significant for insufficient weight gain.

Concerning insufficient weight gain versus adequate weight gain and the remaining variables, this study verified a $30 \%$ rate of insufficient weight gain. A similar value was identified by Andreto et al., ${ }^{20}$ which reported a rate of $31.1 \%$. Although many studies emphasize that excessive weight gain is a matter that requires immediate attention in prenatal care, 15 it is also troublesome to observe that an elevate rate of pregnant women presented insufficient weight gain, which is frequently associated with premature birth and low weight at birth. $20-22$

This fact reinforces the importance of nutritional monitoring in prenatal care, which must focus on modifiable factors, such as weight gain and diet. Both of these benefits women at risk of excessive and insufficient weight gain alike through the monitoring of weight gain and orientations of healthy diet 
practices. ${ }^{23-25}$

In this study, insufficient weight gain was observed in adults $(33.3 \%)$, with unfinished high school $(35.5 \%)$ and with an income up to 1.5 minimal salaries (35.1\%). A study performed in São Paulo demonstrated that the low weight indicated very similar values. In this report, low weight was observed in $33 \%$ of adults with less than 8 years of study $(26.7 \%)$ and with an average income of 1 minimum salary. 14 These findings reinforce the impact of low education level and low income in the low weight during pregnancy, considering that the lack of financial resources and lack of instruction inhibits women from seeking medical assistance, information on diet and nutrition during this period, in addition to the lack of resources necessary for guaranteeing an adequate diet.

Analyzing the habitation of pregnant women and comparing excessive with adequate weight gain, there was no significant difference between rural and urban zone individuals. However, when insufficient gain versus adequate gain were associated with habitation, a tendency of pregnant women from the rural area presenting a risk for insufficient weight gain was observed, 44\% [RR=1.09 (CI95\% $=0.99-$ $1.20)$ ], compared to $28.4 \%$ of risk for those living in

\section{References}

1. Santos MMAS, Baião MR, Barros DC, Pinto AA, Pedrosa PLM, Saunders C. Estado nutricional pré gestacional, ganho de peso materno, condições da assistência pré-natal e desfechos perinatais adversos entre puérperas adolescentes. Rev Bras Epidemiol. 2012; 15 (1): 143-54.

2. Institute of Medicine. Weight gain during pregnancy: reexamining the guidelines. Washington DC: National Academy Press; 2009.

3. Bodnar LM, Hutcheon JA, Platt RW, Himes KP, Simhams $\mathrm{HN}$, Abrams B. Should gestational weight gain recommendacions be tailoed by maternal characteristics? Am J Epidemiol. 2011; 174 (2): 136-46.

4. Vitolo MR, Bueno MSF, Gama CM. Impacto de um programa de orientação dietética sobre a velocidade de ganho de peso de gestantes atendidas em unidades de saúde. Rev Bras Ginecol Obstet. 2011; 33 (1): 13-9.

5. Moura ERF, Oliveira CGS, Damasceno AKC, Pereira MMK. Fatores de risco para a síndrome hipertensiva especifica entre mulheres hospitalizadas com préeclâmpsia. Cogitare Enferm. 2010; 15 (2): 250-5.

6. Marano D, Gama SGN, Pereira APE, Souza PRBJ. Adequação do ganho ponderal de gestantes em dois municípios do Estado do Rio de Janeiro (RJ), Brasil, 2008. Rev Bras Ginecol Obstet. 2012; 34 (3): 102-6.

7. Stulbach TE, Benício MHDA, Andeazza R, Kono S. Determinantes do ganho ponderal excessivo durante a the urban area. It might be considered that pregnant women living in locations far from the urban area may have difficulties in access to prenatal care, havin less access to assistance in this moment; in addition to this, the lifestyle with restriction on energetic consumption of women in the rural area in comparison to those in the urban area have been demonstrated by the POF26 research of 2008-2009. In this report, the deficit of weight in women of the rural area $(5.5 \%)$ surpasses $5 \%$ in Northeastern Brazil, which is critical and higher than the urban area women $(4.5 \%)$.

Socioeconomic factors that were mostly associated with excessive weight gain in pregnant women in this study were age, marital status and employment status. On the other hand, insufficient weight gain was mostly associated with marital status, education level, income and habitation.

In conclusion, the results indicate that socioeconomic characteristics must be considered when monitoring weight gain during pregnancy. These factors seem to determine weight gain, whether excessive or insufficient. Considering that one of the objectives of prenatal care is identifying early risk factors for unfavorable pregnancy outcomes, understanding such factors is indispensable. gestação em serviço público de pré-natal de baixo risco. Rev Bras Epidemiol. 2007; 10 (1): 99-108.

8. Brasil. Ministério da Saúde. Atenção ao pré-natal de baixo risco. Série A. Normas e Manuais técnicos. Cadernos de atenção básica, $n^{0}$ 32. Brasília, DF; 2012.

9. Brasil. Ministério da Saúde. Pré-Natal e Puerpério, Atenção Qualificada e Humanizada. Manual Técnico. Brasília, DF; 2012.

10. Nast M, Oliveira A, Rauber F, Vitolo MR. Ganho de peso excessivo na gestação é fator de risco para o excesso de peso em mulheres. Rev Bras Ginecol Obstet. 2013; 35 (12): 536-40.

11. Gomes RNS, Gomes VTS, Caldas DRC, Lago EC, Campos FKL, Gomes MS. Avaliação do estado nutricional de gestantes atendidas em unidades básicas de saúde. Rev Interd. 2014; 7 (4): 81-90.

12. Silva DG, Macedo NB. Associação entre o ganho de peso e a gestação e o prognóstico da gestação. Sci Med. 2014; 24 (3): 229-36.

13. Drehmer M, Camey S, Schmidt MI, Olinto MT, Giacomello A, Buss C, Melere C, Hoffmann J, Manzolli P, Soares RM, Ozcariz S, Nunes MA. Socioeconomic, demographic and nutritional factors associated with maternal weight gain in general practices in Southern Brazil. Cad Saúde Pública. 2010; 26 (5): 1024-34. 
14. Magalhães EIS, Maia DS, Bonfim CFA, Netto MP, Lamounier JA, Rocha DS. Prevalência e fatores associados ao ganho de peso gestacional excessivo em unidades de saúde do sudoeste da Bahia. Rev Bras Epidemiol. 2015; 18 (4): 858-69.

15. Carvalhaes MABL, Gomes CB, Malta MB, Papini SJ, Parada CM. Pregnancy overweight is associated excessive weight gain during pregnancy. Rer Bras Ginecol Obstet. 2013; 35 (11): 523-9.

16. Brasil. Ministério da Saúde. Manual de técnico do pré-natal e puerpério. Secretaria de saúde do estado de São Paulo. São Paulo, SP; 2010

17. Borelli M, Domene SMA, Mais LA, Pavan J, Taddei JAAC A inserção do nutricionista na atenção básica: uma proposta para o matriciamento da atenção nutricional. Ciênc Saúde Coletiva. 2015; 20 (9): 2765-78.

18. Mancuso ANC, Tonacio LV, Silva ER, Vieira VL. A atuação do nutricionista na atenção básica a saúde em grande centro urbano. Ciênc Saúde Coletiva. 2012; 17 (12): 3289-300.

19. Melo ASO, Assunção PL, Gondim SSR, Carvalho DF, Amorim MMR, Benicio MHD. Estado nutricional materno ganho de peso gestacional e peso ao nascer. Rev Bras Epidemiol. 2011; 10 (2): 249-57.

20. Andreto LM, Souza AI, Figueiroa JN, Cabral-Filho JE. Fatores associados ao ganho de peso ponderal excessivo em gestantes atendidas em um serviço público de pré-natal na cidade de Recife, Pernambuco, Brasil. Cad Saúde Pública. 2006; 22 (11): 2401-09.

Received on March 19, 2018

Final version presented on October 21, 2018

Approved on November 28, 2018
21. Capelli JCS, Pontes JS, Pereira SEA, Silva AAM, Carmo CN, Boccolini CS, Almeida MFL. Peso ao nascer e fatores associados ao período pré natal: um estudo transversal em hospital maternidade de referência. Ciênc Saúde Coletiva. 2014; 19 (7): 2063-72

22. Fraga ACSC, Filha MMT. Factors associated with gestational weight gain in pregnant women in Rio de Janeiro, Brazil, 2008. Cad Saúde Pública. 2014; 30 (3): 633-44.

23. Sato APS, Fujimori E. Estado nutricional e ganho de peso em gestantes. Rev Latino-Am Enfermagem. 2012; 20 (3): 1-7 telas.

24. Accioly E, Saunders C, Lacerda E. Nutrição em Obstetrícia e Pediatria. 2 ed. Rio de Janeiro: Guanabara-Koogan; 2009. p.649.

25. Institute of Medicine. National Research Council. Weight Gain During Pregnancy: Reexamining the Guidelines. Washington (DC): National Academy of Science; 2009.

26. Instituto Brasileiro de Geografia e Estatística. Pesquisa de orçamentos familiares 2008-2009: antropometria e estado nutricional de crianças, adolescentes e adultos no Brasil. Rio de Janeiro: IBGE; 2010. 